\title{
An EOQ model for three parameter Weibull deterioration with permissible delay in payments and associated salvage value
}

\author{
C.K. Tripathy ${ }^{\mathrm{a}^{*}}$ and L. M. Pradhan ${ }^{\mathrm{b}}$
}

${ }^{a}$ Department of Statistics, Sambalpur University, Jyoti Vihar, Sambalpur-768019, India bDepartment of Mathematics, Silicon Institute of Technology, Sason, Sambalpur-768200, India

\begin{tabular}{|c|c|}
\hline ART I C L E I N F O & A B S T R A C T \\
\hline $\begin{array}{l}\text { Article history: } \\
\text { Received } 1 \text { July } 2011 \\
\text { Received in revised form } \\
\text { July, } 29,2011 \\
\text { Accepted } 30 \text { July } 2011 \\
\text { Available online } \\
\text { 30 July } 2011 \\
\text { Keywords: } \\
\text { Weibull deterioration }\end{array}$ & $\begin{array}{l}\text { This paper deals with the development of an inventory model for Weibull deteriorating items } \\
\text { with constant demand when delay in payments is allowed to the retailer to settle the account } \\
\text { against the purchases made. Shortages are not allowed and the salvage value is associated with } \\
\text { the deteriorated units. In this paper, we consider two cases; those are for the case payment } \\
\text { within the permissible time and for payment after the expiry of permissible time with interest. } \\
\text { Numerical examples are provided to illustrate our results. Sensitivity analysis are carried out to } \\
\text { analyze the effect of changes in the optimal solution with respect to change in one parameter at } \\
\text { a time. }\end{array}$ \\
\hline
\end{tabular}

Salvage value

Permissible delay in payments

\section{Introduction}

Generally retailers are encouraged towards bulk purchasing due to the trade credit given by suppliers. No interest is charged if the account is settled within this period. However if the payment is not settled during the period, then interest is charged.

Goyal (1985) is believed to be the first who developed an EOQ model under the condition of permissible delay in payments. He computed interest earned on the sales revenue on unit purchase price. Abad and Jaggi (2003) studied joint approach for setting unit price and the length of the credit period for a seller when end demand is price sensitive. Huang (2003) studied optimal retailer's ordering policies under trade credit financing. Optimal replenishment and payment policies were discussed by Huang and Chung (2003) considering cash discount and trade credit. Teng (2002) and Chung and Liao (2004) studied several models on permissible delay in payments. Chung (2009) investigated a model for deteriorating item with partial backlogging and permissible delay in payments. Chang et al. (2003) and Liao et al. (2000) studied a production planning model under trade credit. Jammal et al. (1997), Sarker et al. (2000), Jaggi et al. (1994), Liao et al. (2007), Shah and Huang, Chung (2003) studied optimal replenishment and payment policies in the EOQ model under cash discount and trade credit. Shah (2006) incorporated various models on permissible delay in payments and concluded that the retailer earn interest generated revenue by delaying the payments up to last date of offered delay period time. Retailers pricing and ordering policies under trade credit in

* Corresponding author Tel.: +919439412131

E-mail: c.tripathy@yahoo.com (C. K. Cripathy) 
declining market was studied by Shah (2010) and concluded that the retailer should buy deteriorated units at a lower price and sell it off at the earliest. Tripathy \& Pradhan (2011) investigated a model of optimal pricing and ordering policy for three parameter Weibull deterioration under trade credit. Tripathy Mishra (2010) studied an EOQ model for linear deteriorating rates with shortages and permissible delay in payments. In developing the present model, demand of a product is assumed to be constant and deterioration is taken as Weibull distribution with three parameters. We have considered the case of no shortages and infinite replenishment rate and the salvage value is associated with the deteriorated units. Our target is to minimize the retailer's total cost. We have calculated the optimal total cost, optimal ordering quantity, and optimal cycle length for our model. Numerical examples are given to illustrate the model. Sensitivity analysis has also been carried out to observe the effects of various parameters on the optimal total cost and optimal cycle time.

\section{Notations and assumptions}

We need the following notations and assumptions to develop the proposed mathematical model.

\section{Notations:}

$R$ : demand rate per unit of time,

$C$ : the unit purchase cost,

$P$ : the unit selling price with $(P>C)$,

$h$ : the inventory holding cost per unit per year excluding interest charges,

$A$ : the ordering cost per order,

$M$ : the permissible credit period offered by the supplier to the retailer for settling the account,

$I_{c}$ : the interest charged per monetary unit in stock per annum by the supplier,

$I_{e}$ : the interest earned per monetary unit per year, where $I_{e}<I_{c}$,

$Q$ : the order quantity,

$\theta=\alpha \beta(t-\gamma)^{\beta-1}$ : where $0 \leq \alpha<1$ is the scale parameter and $\beta \geq 1$ is the shape parameter and $\gamma>0$ is the location parameter,

$T$ : the cycle time.

\section{Assumptions}

(i) The inventory system under consideration deals with single item.

(ii) The planning horizon is infinite.

(iii)The demand of the product is constant. Shortages are not allowed and lead-time is zero.

(iv) The deteriorated units can neither be repaired nor be replaced during the cycle time. It follows three-parameter Weibull distribution.

(v) The retailer can deposit generated sales revenue in an interest bearing account during the permissible credit period. At the end of this period, the retailer settles the account for all the units sold keeping the difference for day-to-day expenditure, and paying the interest charges on the unsold items in the stock.

(vi) The salvage value $a C(0 \leq a<1)$ is associated to deteriorated units during the cycle time.

\section{Mathematical model}

At any instant of time $t(0 \leq t \leq T)$, let $Q(t)$ be the on-hand inventory. Since the depletion of units is due to demand and deterioration, the rate of change of inventory level is governed by the following differential equation:

$$
\frac{d Q(t)}{d t}+\theta Q(t)=-R \quad 0 \leq t \leq T
$$

subject to the boundary conditions $Q(0)=Q$ and $Q(T)=0$. 
Since $\alpha$ is very small using series expansion ignoring the second and higher powers of $\alpha$, the solution of Eq. (1) is as follows,

$Q(t)=R\left[(T-t)+\frac{\alpha\left((T-\gamma)^{\beta+1}-(t-\gamma)^{\beta+1}\right)}{\beta+1}-\alpha(T-t)(t-\gamma)^{\beta}\right]$.

Using $Q(0)=Q$ in Eq. (2), we have procurement quantity as,

$Q(t)=R\left[T+\frac{\alpha\left((T-\gamma)^{\beta+1}-(-\gamma)^{\beta+1}\right)}{\beta+1}-\alpha T(-\gamma)^{\beta}\right]$.

During one cycle the number of units that deteriorate is

$$
D=D(T)=Q-R T=\frac{\alpha R\left((T-\gamma)^{\beta+1}-(-\gamma)^{\beta+1}\right)}{\beta+1}-\alpha R T(-\gamma)^{\beta} .
$$

Cost due to deterioration is

$C D=\frac{\alpha R C\left((T-\gamma)^{\beta+1}-(-\gamma)^{\beta+1}\right)}{\beta+1}-\alpha R T C(-\gamma)^{\beta}$.

Salvage value of deteriorated units is

$$
S V=a C D=\frac{\alpha R C a\left((T-\gamma)^{\beta+1}-(-\gamma)^{\beta+1}\right)}{\beta+1}-\alpha R T C a(-\gamma)^{\beta} .
$$

The inventory holding cost is

$$
\begin{aligned}
& I H C=h \int_{0}^{T} Q(t) d t=h R \int_{0}^{T}\left[(T-t)+\frac{\alpha\left((T-\gamma)^{\beta+1}-(t-\gamma)^{\beta+1}\right)}{\beta+1}-\alpha(T-t)(t-\gamma)^{\beta}\right] d t \\
&=h R\left[\frac{T^{2}}{2}+\frac{\alpha T\left((T-\gamma)^{\beta+1}+(-\gamma)^{\beta+1}\right)}{\beta+1}+\frac{2 \alpha\left((-\gamma)^{\beta+2}-(T-\gamma)^{\beta+2}\right)}{(\beta+1)(\beta+2)}\right] .
\end{aligned}
$$

Ordering cost is

$$
O C=A
$$

Now we consider the two cases based on the length of $T$ and $M$, using the fact that interest charged or earned (i.e., costs (d) and (e) in section 2.2),

\section{Case -I: $M \leq T$}

The retailer can sale units during $[0, M]$ at a sale price $P$ per unit which he can put an interest rate $I_{e}$ per unit per annum in an interest bearing account. So the total interest earned during $[0, M]$ is $I E_{1}=P I_{e} \int_{0}^{M} R t d t=\frac{P I_{e} R M^{2}}{2}$.

Again, the total interest charges payable by the retailer during $[M, T]$ is

$$
\begin{aligned}
I C_{1}=C I_{c} \int_{M}^{T} Q(t) d t & =C I_{c} R\left[\frac{T^{2}}{2}+\frac{M^{2}}{2}-T M+\frac{\alpha(T-\gamma)^{\beta+1}(T-M)}{(\beta+1)}+\frac{2 \alpha\left((M-\gamma)^{\beta+2}-(T-\gamma)^{\beta+2}\right)}{(\beta+1)(\beta+2)}\right. \\
& \left.+\frac{\alpha(M-\gamma)^{\beta+1}(T-M)}{(\beta+1)}\right]
\end{aligned}
$$

Total cost $K_{1}(T)$ per time unit is 


$$
\begin{aligned}
K_{1}(T) & =\frac{1}{T}\left[O C+I H C+C D+I C_{1}-I E_{1}-S V\right] \\
& =\frac{A}{T}+h R\left[\frac{T}{2}+\frac{\alpha\left((T-\gamma)^{\beta+1}+(-\gamma)^{\beta+1}\right)}{\beta+1}+\frac{2 \alpha\left((-\gamma)^{\beta+2}-(T-\gamma)^{\beta+2}\right)}{T(\beta+1)(\beta+2)}\right] \\
& +\frac{\alpha R C(1-a)\left((T-\gamma)^{\beta+1}-(-\gamma)^{\beta+1}\right)}{(\beta+1) T}-\alpha R C(1-a)(-\gamma)^{\beta} \\
& +C I_{c} R\left[\frac{T}{2}+\frac{M^{2}}{2 T}-M+\frac{\alpha(T-\gamma)^{\beta+1}(T-M)}{T(\beta+1)}+\frac{2 \alpha\left((M-\gamma)^{\beta+2}-(T-\gamma)^{\beta+2}\right)}{T(\beta+1)(\beta+2)}\right. \\
& \left.+\frac{\alpha(M-\gamma)^{\beta+1}(T-M)}{T(\beta+1)}-\frac{P I_{e} R M^{2}}{2 T}\right] .
\end{aligned}
$$

To find out the values of $T$ for which the Total cost is minimum the necessary condition is $\frac{\partial K_{1}}{\partial T}=0$

$$
\begin{aligned}
\Rightarrow- & \frac{A}{T^{2}}+h R\left[\frac{1}{2}+\alpha(T-\gamma)^{\beta}-\frac{2 \alpha\left((-\gamma)^{\beta+2}-(T-\gamma)^{\beta+2}\right)}{T^{2}(\beta+1)(\beta+2)}-\frac{2 \alpha(T-\gamma)^{\beta+1}}{T(\beta+1)}\right] \\
& -\frac{\alpha R C(1-a)\left((T-\gamma)^{\beta+1}-(-\gamma)^{\beta+1}\right)}{(\beta+1) T^{2}}+\frac{1}{T} \alpha R C(1-a)(T-\gamma)^{\beta} \\
+ & C I_{c} R\left[\frac{1}{2}-\frac{M^{2}}{2 T^{2}}-M+\frac{\alpha(T-\gamma)^{\beta}(T-M)}{T}-\frac{2 \alpha\left((M-\gamma)^{\beta+2}-(T-\gamma)^{\beta+2}\right)}{T^{2}(\beta+1)(\beta+2)}\right. \\
+ & \left.\frac{\alpha(T-\gamma)^{\beta+1} M}{T^{2}(\beta+1)}-\frac{2 \alpha(T-\gamma)^{\beta+1}}{T(\beta+1)}+\frac{\alpha(M-\gamma)^{\beta+1} M}{T^{2}(\beta+1)}+\frac{P I_{e} R M^{2}}{2 T^{2}}\right]=0
\end{aligned}
$$

\section{Case -II: $M>T$}

Here, the credit period offered by the supplier to the retailer is greater than the cycle time. Hence, interest charges are zero.

$I C_{2}=0$

and the interest earned per time unit is

$$
I E_{2}=P I_{e}\left[\int_{0}^{T} R t d t+R T(M-T)\right]==P I_{e} R\left(M-\frac{T}{2}\right)
$$

The total cost; $K_{2}(T)$ per time unit is

$$
\begin{aligned}
K_{2}(T)= & \frac{1}{T}\left[O C+I H C+C D+I C_{2}-I E_{2}-S V\right] \\
= & \frac{A}{T}+h R\left[\frac{T}{2}+\frac{\alpha\left((T-\gamma)^{\beta+1}+(-\gamma)^{\beta+1}\right)}{\beta+1}+\frac{2 \alpha\left((-\gamma)^{\beta+2}-(T-\gamma)^{\beta+2}\right)}{T(\beta+1)(\beta+2)}\right] \\
& +\frac{\alpha R C(1-a)\left((T-\gamma)^{\beta+1}-(-\gamma)^{\beta+1}\right)}{(\beta+1) T}-\alpha R C(1-a)(-\gamma)^{\beta}-P I_{e} R\left(\frac{M}{T}-\frac{1}{2}\right)
\end{aligned}
$$


The necessary condition for $K_{2}$ to be minimum is given by the equation $\frac{\partial K_{2}}{\partial T}=0$

$$
\begin{aligned}
& \Rightarrow-\frac{A}{T^{2}}+h R\left[\frac{1}{2}+\alpha(T-\gamma)^{\beta}-\frac{2 \alpha\left(T(\beta+2)(T-\gamma)^{\beta+1}+(-\gamma)^{\beta+2}-(T-\gamma)^{\beta+2}\right)}{T^{2}(\beta+1)(\beta+2)}\right] \\
& +\frac{\alpha R C(1-a)\left((T-\gamma)^{\beta} T(\beta+1)-(T-\gamma)^{\beta+1}+(-\gamma)^{\beta+1}\right)}{(\beta+1) T^{2}}+\frac{P I_{e} R M}{T^{2}}=0,
\end{aligned}
$$

which minimizes $K_{2}$ only if $\frac{\partial^{2} K_{2}}{\partial T^{2}}>0, \forall T$.

\section{Numerical Examples}

\section{Example 1: (Case -I: $M \leq T$ )}

Let $\quad, \quad\left[A, C, h, P, \alpha, \beta, \gamma, a, R, I_{c}, I_{e}, M\right]=[500,40,4,100,0.4,20,0.6,0.4,1000,0.16,0.04,0.0548]$ in appropriate units. Using the Eq. (12) and Eq. (11) and by the help of Mathematica 5.1 software, we can obtain the optimum solution as

$T=0.311205, \quad K_{1}=2885.5, \quad \frac{\partial^{2} K_{1}}{\partial T^{2}}=33418.5>0$. Here it is clearly seen that $M \leq T$.

\section{Example 2: ( Case -II: $M>T$ )}

Let , $\left[A, C, h, P, \alpha, \beta, \gamma, a, R, I_{e}, M\right]=[500,40,4,100,0.4,20,0.6,0.4,1000,0.01,0.4$, ]in appropriate units. By the help of Mathematica 5.1 software in Eq. (16) and Eq. (15) we obtain the optimum solution for the cycle time $T$ and the total cost $K_{2}$ as $T=0.223618, K_{2}=1394.12$.

Here it is clearly seen that $M>T$. So this belongs to the case-II.

\section{Sensitivity Analysis}

We have performed sensitivity analysis by changing parameters $A, C, h, P, \alpha, \beta, \gamma, a, R I_{c}, I_{e}, M$, as $-50 \%,-25 \%, 25 \%$ and $50 \%$ and keeping the remaining parameters at their original values. The original values are taken from example 1 above. The corresponding changes in the cycle time and the total cost are exhibited in Table 1.

The observations found from the Table 1 are as follows:

The optimal cycle time is directly proportional to the ordering cost, scale parameter, location parameter and the allowable credit period whereas it is inversely proportional to the purchase cost, inventory holding cost, unit selling price, shape parameter, the salvage value, demand rate, interest charged and interest earned of the system. Similarly the total cost of the system is directly proportional to the ordering cost, purchase cost, inventory holding cost, the salvage value, demand rate, scale parameter, and interest charged per unit of the system whereas it is inversely proportional to the unit selling price, scale parameter, location parameter, interest earned and the allowable credit period of the system. Again the optimal cost shows variable changes with the change in the shape parameter. Now changing the values of a parameter keeping the remaining parameters at their original value the corresponding changes in the cycle time and the total cost are exhibited in table 2 below. Here the original values are taken from the second example. 


\section{Table 1}

Case -I $(M \leq T)$

\begin{tabular}{|c|c|c|c|}
\hline parameter & \% change & $T$ & $K$ \\
\hline \multirow{4}{*}{ A } & -25 & 0.269834 & 2455.23 \\
\hline & 25 & 0.347688 & 3264.92 \\
\hline & 50 & 0.380691 & 3608.15 \\
\hline & -50 & 0.372232 & 2504.55 \\
\hline \multirow{4}{*}{ C } & -25 & 0.337507 & 2706.78 \\
\hline & 25 & 0.290407 & 3046.09 \\
\hline & 50 & 0.273437 & 3192.19 \\
\hline & -50 & 0.346277 & 2557.69 \\
\hline \multirow{4}{*}{$h$} & -25 & 0.327340 & 2725.96 \\
\hline & 25 & 0.297243 & 3037.53 \\
\hline & 50 & 0.285005 & 3183.02 \\
\hline & -50 & 0.312131 & 2895.13 \\
\hline \multirow{4}{*}{$P$} & -25 & 0.311669 & 2890.32 \\
\hline & 25 & 0.310741 & 2880.67 \\
\hline & 50 & 0.310276 & 2875.83 \\
\hline & -50 & 0.311204 & 2885.66 \\
\hline \multirow{4}{*}{$\alpha$} & -25 & 0.311204 & 2885.58 \\
\hline & 25 & 0.311206 & 2885.42 \\
\hline & 50 & 0.311207 & 2885.34 \\
\hline & -50 & 0.312204 & 2837.41 \\
\hline \multirow{4}{*}{$\beta$} & -25 & 0.311149 & 2889.81 \\
\hline & 25 & 0.311202 & 2885.84 \\
\hline & 50 & 0.311202 & 2885.81 \\
\hline & -50 & 0.311202 & 2885.82 \\
\hline \multirow{4}{*}{$\gamma$} & -25 & 0.311202 & 2885.82 \\
\hline & 25 & 0.311544 & 2858.69 \\
\hline & 50 & 0.326614 & 1867.22 \\
\hline & -50 & 0.311206 & 2885.39 \\
\hline \multirow{4}{*}{$a$} & -25 & 0.311206 & 2885.44 \\
\hline & 25 & 0.311205 & 2885.55 \\
\hline & 50 & 0.311204 & 2885.60 \\
\hline & -50 & 0.439321 & 2108.95 \\
\hline \multirow{4}{*}{$R$} & -25 & 0.359026 & 2537.13 \\
\hline & 25 & 0.278600 & 3183.00 \\
\hline & 50 & 0.254553 & 3444.47 \\
\hline & -50 & 0.372234 & 2504.39 \\
\hline \multirow{4}{*}{$I_{c}$} & -25 & 0.337508 & 2706.70 \\
\hline & 25 & 0.290406 & 3046.17 \\
\hline & 50 & 0.273436 & 3192.35 \\
\hline & -50 & 0.312131 & 2895.13 \\
\hline \multirow{3}{*}{$I_{e}$} & -25 & 0.311669 & 2890.32 \\
\hline & 25 & 0.310741 & 2880.67 \\
\hline & 50 & 0.310276 & 2875.83 \\
\hline \multirow{4}{*}{$M$} & -50 & 0.310369 & 3052.14 \\
\hline & -25 & 0.310718 & 2968.10 \\
\hline & 25 & 0.311831 & 2804.33 \\
\hline & 50 & 0.312594 & 2724.59 \\
\hline
\end{tabular}


Table 2

Case -II $(M>T)$

\begin{tabular}{|c|c|c|c|}
\hline parameter & Value changed & $T$ & $K_{2}$ \\
\hline \multirow{5}{*}{$A$} & 450 & 0.158130 & 1132.17 \\
\hline & 550 & 0.273871 & 1595.13 \\
\hline & 600 & 0.316236 & 1764.59 \\
\hline & 650 & 0.353560 & 1913.89 \\
\hline & 700 & 0.387305 & 2048.87 \\
\hline \multirow{5}{*}{$h$} & 2 & 0.316244 & 1132.14 \\
\hline & 8 & 0.158122 & 1769.62 \\
\hline & 10 & 0.141428 & 1913.93 \\
\hline & 15 & 0.115476 & 2231.78 \\
\hline & 20 & 0.100005 & 2499.74 \\
\hline \multirow{5}{*}{$P$} & 50 & 0.387302 & 1798.87 \\
\hline & 60 & 0.360559 & 1741.9 \\
\hline & 70 & 0.331666 & 1676.33 \\
\hline & 80 & 0.300004 & 1599.68 \\
\hline & 90 & 0.264580 & 1507.99 \\
\hline \multirow{5}{*}{$R$} & 800 & 0.335414 & 1473.05 \\
\hline & 850 & 0.306790 & 1467.8 \\
\hline & 900 & 0.278890 & 1453.71 \\
\hline & 950 & 0.251317 & 1429.69 \\
\hline & 1100 & 0.161520 & 1276.5 \\
\hline \multirow{5}{*}{ C } & 10 & 0.223610 & 1394.35 \\
\hline & 25 & 0.223614 & 1394.23 \\
\hline & 30 & 0.223615 & 1394.2 \\
\hline & 40 & 0.223618 & 1394.12 \\
\hline & 50 & 0.223621 & 1394.04 \\
\hline \multirow{5}{*}{$\alpha$} & 0.5 & 0.223621 & 1394.04 \\
\hline & 0.6 & 0.223624 & 1393.97 \\
\hline & 0.7 & 0.223627 & 1393.89 \\
\hline & 0.8 & 0.223629 & 1393.81 \\
\hline & 0.9 & 0.223632 & 1393.74 \\
\hline \multirow{5}{*}{$\beta$} & 10 & 0.227027 & 1350.06 \\
\hline & 15 & 0.223416 & 1398.2 \\
\hline & 22 & 0.223611 & 1394.32 \\
\hline & 40 & 0.223607 & 1394.43 \\
\hline & 45 & 0.223607 & 1394.43 \\
\hline \multirow{5}{*}{$\gamma$} & 0.4 & 0.223607 & 1394.43 \\
\hline & 0.5 & 0.223607 & 1394.42 \\
\hline & 0.7 & 0.223894 & 1301.91 \\
\hline & 0.8 & 0.228289 & 1387.88 \\
\hline & 0.9 & 0.274265 & 422.441 \\
\hline \multirow{5}{*}{$I_{e}$} & 0.01 & 0.223618 & 1394.12 \\
\hline & 0.011 & 0.17322 & 1242.53 \\
\hline & 0.0115 & 0.141439 & 1140.40 \\
\hline & 0.012 & 0.100022 & 999.746 \\
\hline & 0.0122 & 0.077484 & 919.609 \\
\hline
\end{tabular}

The observations found from Table 2 are as follows. The optimal cycle time is directly proportional to the ordering cost, purchase cost, scale parameter, location parameter whereas it is inversely proportional to the inventory holding cost, unit selling price, demand rate, and interest earned of the system. Again, it shows variable changes with the change in the shape parameter. Similarly the total cost of the system is directly proportional to the ordering cost, inventory holding cost and the shape parameter whereas it is inversely proportional to demand rate, unit selling price, purchase cost, scale 
parameter, and interest earned per unit of the system. Again the optimal cost shows variable changes with the change in the location parameter.

\section{Conclusion}

The model developed in this paper assumes three parameter Weibull deterioration, salvage value and delay in payments. Shortages are not allowed and replenishment rate is infinite. It has been observed from the sensitive analysis that the total cost reduces when we increase the selling price or credit period or interest earned of the system. Total cycle time reduces when we reduce the ordering cost or scale parameter or location parameter or credit period of the system. Also it reduces when we increase holding cost, demand rate, selling price, interest earned of the system.

\section{References}

Abad, P.L., \& Jaggi, C.K. (2003). A joint approach for setting unit price and the length of the credit period for a seller when end demand is price sensitive. International Journal of Production Economics, 83,115122.

Chang, C. T., Ouyang, L.Y., Teng, J.T. (2003). An EOQ model for deteriorating items under supplier credits linked to ordering quantity. Applied Mathematical Modelling. 27, 983 - 996.

Chung, K. J., \& Huang, C. K. (2009). An ordering policy with allowable shortage and permissible delay in payments. Applied Mathematical Modelling, 33, 2518-2525.

Chung, K. J., \& Liao J.J. (2004). Lot-sizing decisions under trade credit depending on the ordering quantity. Computers and Operations Research, 31, 909-928.

Goyal, S. K. (1985). Economic order quantity under conditions of permissible delay in payments. Journal of the Operational Research Society, 36, 335 - 338.

Huang, Y. F. (2003). Optimal retailer's ordering policies in the EOQ model under trade credit financing. Journal of the Operational Research Society, 54, 1011-1015.

Huang, Y.F., \& Chung, K.J. (2003). Optimal replenishment and payment policies in the EOQ model under cash discount and trade credit. Asia-Pacific Journal of Operational Research, 20, 177-190.

Jamal, A. M. M., Sarker, B.R., \& Wang, S. (1997). An ordering policy for deteriorating items with allowable shortages and permissible delay in payment. Journal of the Operational Research Society, 48, 826 - 833.

Jamal, A. M. M., Sarker, B. R., Wang, S. (2000). Optimal payment time for a retailer under permitted delay of payment by the wholesaler. International Journal of Production Economics, 66, $59-66$.

Liao, H. C., Tsai, C.H., Su, C. T. (2000). An inventory model with deteriorating items under inflation when a delay in payments is permissible. International Journal of Production Economics, 63, 207- 214.

Ouyang, L. Y., TENG, J. T., \& CHEN, L. H. (2006). Optimal ordering policy for deteriorating items with partial backlogging under permissible delay in payments. Journal of Global Optimization, 34, 245- 271.

Ouyang, L. Y., TENG, J. T., GOYAL, S. K., \& YANG, C. T. (2009). An economic order quantity model for deteriorating items with partially permissible delay in payments linked to order quantity. European Journal of Operational Research, 194, $418-431$.

Sarker, B. R., JAMAL, A. M. M., \& WANG, S. (2000). Optimal payment time under permissible delay for production with deterioration. Production planning and Control, 11,380 -390.

Shah, N. H. (2006). Inventory model for deteriorating items \& time value of money for a finite time horizon under the permissible delay in payments. International Journal in System Sciences, 37, 9-15.

Shah, N. H., \& Raykundaliya, N. (2010). Retailers Pricing \& Ordering Strategy for Weibull Distribution Deterioration under trade credit in declining market. Applied Mathematical Sciences, 4, 21, 1011-1020.

Teng, J.T, (2002). On the Economic Order Quantity under conditions of permissible delay in payments, Journal of the Operational Research Society. 53, 915-918.

Tripathy, C.K., \& Pradhan L.M. (2011). Optimal Pricing \& Ordering Policy for three parameter Weibull deterioration under trade credit. International Journal of Mathematical Analysis, 5(6), 275-284.

Tripathy, C.K. \& Mishra U. (2010). An EOQ Model for Linear Deteriorating Rates with Shortage and Permissible Delay in Payment, The IUP Journal of Operations Management, 4(4), 7-20. 